\title{
Beyond Bologna: The Sustainable University Enterprises Partnership
}

\author{
Alessandro Figus \\ Link Campus University, Rome, Italy
}

\begin{abstract}
There is a necessity to understand the effects of the globalization on the labor market concerning job markets. The economic and cultural growth and the ability of renewal are the fundamental objectives of every country, and they should also be the main objective of developing and in-transition countries. This is, particularly important in European Eastern countries. The article analyses university-enterprise partnership projects of the European Union. A series of recommendations has been elaborated for Higher Education Institutions, in particular, European Universities intending to progress further with the critical dimension of University-Enterprise cooperation as one of the key elements to enhance their competitiveness, and contribute to EU policy and activities in this area. These recommendations will be based on the findings of the online survey, the case studies and the discussions between all stakeholders of the European Conference held in Bonn on 18-19 June 2007. The qualitative effectiveness of the "higher education product" depends conclusively on the human components - teacher, in the first place, their behavior, competence, and attitudes.
\end{abstract}

\section{INTRODUCTION}

In the framework of the Conference on Education Quality held by Technical University of Novosibirsk in Novosibirsk in May 2003 under the financial support of the World Bank for Reconstruction, researcher's intervention has been dedicated to the importance of the relationship between the labour market and the "Academic World"; a necessary effort to understand the effects of the globalization on the labour market. In fact, sustainable development is the biggest challenge to world universities during the period of globalization concerning the labour market demand change. Qualitative effectiveness of the people is the result of the "higher education" and it depends conclusively on the "performances" of the human component - the teacher in the first place, and students in the second place (van Weenen, 2000).

The economic and cultural growth and the ability of renewal are the fundamental objectives of every country. These objectives should also be for developing and in-transition countries of Eastern Europe. An important contribution to the attainment of such an objective can be brought by a suitable higher education quality that aims the development of creativity and individual initiative, as well as the acquisition of competencies that improve the professional qualification of the teaching staff.

In contrast to the past, today, in globalisation time, the competitive advantage of a country depends on more human resources and less on the value of materials, capitals, and technologies.

The quality of the higher education has to satisfy the individual cultural needs, and the knowledge and experience needs of the workplace. So, the main objective to reach this quality is to favor the partnership between individuals, businesses, interest-based organizations, and in our case the sustainable partnership between enterprises and the academic world.

As underlined by the various Resolutions of the Council of the European Community it is important for university students to not only attain a good cultural level from a quality education content but also it is crucial to acquire "higher education with strong practical character. 


\author{
Alessandro Figus \\ Beyond Bologna: The Sustainable University Enterprises Partnership
}

To such intention, it is ascertained that there are prefigured forms of organization in European economic world - organizations that are very different from traditional and hierarchical ones. Such organizations are characterised by integration and their strong orientation to the communication. In the globalization era, we remark that there is no big difference between Europe and the Eastern Europe considering all member countries and including countries like Moldova where there is a flow of immigration mainly caused by the retrieval of jobs and problems to find a good job.

\title{
2. EUROPEAN AND EASTERN EUROPE EXPERIENCE
}

Today, there is a high need in Moldova Universities to develop sustainable partnerships with enterprises. For this, universities are needed to modernize their governance and the mode of their operation to respond to the needs of society and transfer of knowledge. By producing fully employable students (Bologna Process), promoting entrepreneurship, contributing to the lifelong learning agenda (in retraining the workforce) and transferring their research results, universities can be strong players in the Lisbon Agenda and contribute to the economic development.

It is clear that both universities and enterprises benefit from closer cooperation. However, many universities still lack an entrepreneurial spirit and they are too academically oriented. Besides, they do not put the relevance of their programs to the needs of the labor market sufficiently high priority.

The scheme of the development of the partnership between universities and enterprises of the European Union has produced a number of recommendations for Higher Education Institutions. European Universities intend to further progress with the important dimension of University-Enterprise cooperation as one of the key elements to enhance Europe's competitiveness and contribute to the EU policy and activities in this area. These recommendations are based on the findings of the online survey, the case studies and the discussions between all stakeholders of the European Conference held in Bonn on 18-19 June 2007. This experience can be the basis of the economic growth for developing countries of Europe, particularly post-Soviet ones - including Moldova. It is obvious through global economic crisis that Moldova is economically suffering. There is no escape for the young people; the only possible solution is the education. Therefore, there is an agenda for the Moldovan Universities to increase their attractiveness through a high rate of employability of graduate students.

We have a greater sense of urgency brought by the Lisbon Agenda and the Bologna Process. The new challenges which confront society as a whole are the demographics of ageing; globalization; climate change and sustainable development; the irreversible rise of information and communication technologies. It is beneficial for Moldova to eliminate its disparity with Europe and to halt the immigration. Therefore, it becomes essential to establish a quality higher education path that can exclusively overcome the technical-operational dimension, offer attractive instruments to develop communication and the ability to work in groups with the purpose of improving the relationships between different functions in the student-teacher bond.

We witnessed new university courses last years in Italy. However, they are not able to provide necessary "complementary" preparation to satisfy the expectations expressed in the market (sometimes universities employ teachers who are not specifically prepared.) Moreover, the market is polluted by parallel higher educational initiatives, for instance, proposal by organizations of recent origin to know its substantial reliability. The excess of offers in comparison to the question produces confusion among the students and the possible users of these courses (like enterprises, public corporate body, and private) that sometimes they are disorientated and often change directions or they prefer to abdicate.

In this context, it is possible to pursue excellent objectives. Also, in higher education it is not a fashion but is an authentic necessity to be competitive in the market and to have the concrete opportunities of work. Therefore, the culture of quality has positive aspects in comparison to the development of 


\section{Alessandro Figus \\ Beyond Bologna: The Sustainable University Enterprises Partnership}

philosophy more directed to the users. In pure market logic it can be defined as "customer".

Considering that the universities offer a service for a long time, they can make reference to the norm ${ }^{1}$ for the realization and the maintenance of a proper quality control. However, it should involve the whole scholastic community and only to the highest level. The key role of standards has been recognized from a long time in the university education programs covering a broad variety of technical sectors.

However, it will be necessary to have a periodic re-examination of the perception that the student has some service furnished with the purpose to improve:

1. The performances;

2. The productivity and the costs;

3. The knowledge and the management of the needs of the higher educational market.

Moreover, it needs to be considered that such a norm, also usable like the reference of certification, represents a complete model of the necessary requisites to build a quality system of higher education area, culturally projected toward the general principles of the "total quality". The adoption of a quality system can introduce some conceptual difficulties for the greater part of the higher education societies, often characterized by organisational structures "craft made", distant from the full awareness of the qualitative requisite of the "higher educational product". But such difficulties do not have to be for the higher-level of higher education that is for the university.

For instance, if we consider the norm ISO the quality it has defined as "The whole of characteristics of a product or a service that confers to it the ability to satisfy the express or implicit demands". From this interpretation, it derives that a control of the quality of higher education will be effective if, and only if, the performances supplied assure the satisfaction of the expectations of the students and consequently of the world of the work.

The final outcome is the result of an organizational trial that must be planned and verified since the beginning, starting from the necessary cognitive activity to obtain student needs in comparison to the "higher educational product". In this case, the university structure would have "to test" the sample "student" in order to locate, analytically, the qualitative requisites of the service, the input of the planning process.

The cognitive investigation must have affected considering that the recipients of the "higher educational products" can be divided into three large categories correspondents to the different personal motivations:

1. acquisition of a culture and professionalism suitable to the expectations of higher educational market and complementary to a working world;

2. development of the competitive basis for a professional career "of success" after the attainment of the higher educational qualification;

3. the necessity of bringing up to date higher educational in relation work activities.

Besides, the process of planning has to be preceded by a careful comparison among question and offers that underline the possible gap compared to the priorities dictated by the market of work. Among suppliers of higher educational services and students, there are now more direct relationships for the search of new forms of equilibrium between the ability of innovation and the question of the market. The analysis of this last one has, in fact, shown the necessity of human resources with welldefined characteristics. In short, there are:

${ }^{1}$ See ISO 9001 or after International Standardization and Education, http://www.iso.org. 


\section{Alessandro Figus \\ Beyond Bologna: The Sustainable University Enterprises Partnership}

1. good training - cultural, general and specific;

2. spirit of initiative;

3. quickness of decision;

4. availability to accept responsibilities;

5. communication ability;

6. workgroup ability;

7. professional competencies that improve the higher education quality also in relation to the world of work.

There is then the planning of the process of planning, the inside of which is distinguished by different phases that go from the layout and elaboration of the "higher educational product", and consequent quality control and verification of the service distributing to the appraisal of the perceptible quality by the student that in turn, in the exercise of its profession will have to integrate himself into the world of work. A different line of this tendency exists to affirm of new organizational methods for the adoption of the keys of co-planning, are that it brings students and their future world of the work intersects and compares their respective professionalisms in order to arrive at joint elaboration of competitive solutions. The activity of verification can be effected measuring the qualitative level of learning of the subjects that receive higher education through evaluations (by means of questionnaires, tests of evaluation, exercises and practical exercises) from which one can derive preventive and corrective actions to eliminate the causes and the errors of not conforming in the progress of allocation of the higher educational service.

The qualitative effectiveness of the "higher education product" depends conclusively on the human components of the teacher, in the first place, their behaviour, their competence, and attitudes. For behaviour we intend above all the availability to the self-critical in comparison to the activity of teaching, the wish to collaborate and to listen to the students, the ability to cover the role of moderator of the classroom. Particularly, competence is expounded, through a theoretical knowledge and practice of the subject, as well as for the didactic methodologies (higher educational)) to facilitate its learning.

Nevertheless, the specialized preparation of the teacher is not enough if it is not accompanied by particular abilities of communication, inside of which it's possible to distinguish characteristics like the ability to capture the attention of the "students stage", the use of language suitable to the cultural level of the student, the attitude to transmit one's own knowledge, and to "to defeat" the natural resistance of the students and in general of individuals "to listen" to new subjects.

In the planning of a university higher education course, but not only, it is, therefore opportune, to define the profile of the human resources and the roles (teacher, tutor, etc.) necessary to carrying out the didactic/higher educational activities. It's not an easy task for the teachers to renovate their methodology of didactical approach to assure a high level of knowledge transfer.

In the didactic activity, the teacher can use methodologies that facilitate the transfer of knowledge and facilitate learning. The theoretical lessons can be for instance assisting from transparent, dispensations, photos, film, graphic representations and demonstration of software products, without skipping practical exercises, in groups or individually. The teacher does not have to have on exclusive preference for a theoretical approach, to avoid the risk that the student assumes a passive role and that the communication which results is notably compromised. Learning also directed to practice, allows a driven discovery of the subject and a reduction of the possible differences between transmitted contents and real situations of work. In the work group, it is possible to overcome the student's reticence to speak from fear of appearing ridiculous in the case of error.

The work group has to use techniques and tools (matrixes, brainstorming, diagram of affinity etc.) for the discussion and increase the objectivity of the results, allowing it to overcome the limits, to the increase the availability of psychological limits to the comparison and to win the preconceptions toward other people's ideas without penalizing creativeness. 


\author{
Alessandro Figus \\ Beyond Bologna: The Sustainable University Enterprises Partnership
}

The higher education quality, the further to have as objective the exaltation of the characteristic of human resources has to neglect training in comparison to the technical aspects. Moreover, in the planning of a course, it is beneficial to program the activity of training according to a run of articulated learning in forms, for each of which the subjects and the times of carrying out must be identified.

It is opportune to confirm that given the quality, any higher educational course has to be projected on the base of the different needs of the student and at the same time of the work market. Nonetheless, it must be structured in a flexible way, so as to be able to adapt to every possible change. The verification of the qualitative effectiveness above of a university higher educational course is immediate, in how much contemporarily to the disbursement of the service the answer of the student is evaluations. In conclusion, the criticisms do not have to be considered an index of failure, but instead of improvement for future projects.

Saying that this is the construction of a plan in which intervenes and in which strategies coincide among the work market toward the world university part of the idea of a project framed to academic context for European Eastern countries following exactly the Bologna principles and recommendations (indicate in the report) of the "Bonn declaration on university-enterprise cooperation ${ }^{2}$ in the context of lifelong learning" and observing the partnership between world market and the academic world. I hope it will be applied quickly particularly in Eastern Europe and in our case it is interesting to find an application in Moldova, it will be possible only through strategic planning, through carrying out feasible projects.

It considers new European Union experience as the European Union Forum for University-Business Dialogue launched in 2008 by the European Commission for smart, sustainable and inclusive growth ${ }^{3}$.

Educational Institutions and especially the Universities are the producers of human capital. As the principal producers of human capital, HEIs must plan in their production of this capital in view of the work market dynamics and in consideration of the challenges of their various backgrounds to overcome these challenges to assure a sustainable development.

The University-enterprise collaboration requires shared interest to explain a particular problem. Whether it is student assignment or the move of research or spin-off, it growth only if the partners cannot obtain the same results on their own. The project's approach is to guarantee that universityenterprise relationship provides an "added supplementary value" from shared effort in: a) setting the qualifications frameworks as the reference points for labour market needs analyses, skills shortage analyses, career guidance, continuing professional development ${ }^{4} ;$ b) outlining the pedagogical component of university-enterprise partnership and the real contribution which it makes to competency based training; c) entrepreneurship education, as an important element of curricular reform within the LLL frame; d) development of training materials and courses towards industry needs.

The educational target is to graduate as better professionals with knowledge and skills needed to succeed in the highly competitive world of today and tomorrow. UNESCO proposed that the vision of education for sustainable development is the world where everyone has the opportunity to benefit from quality education and learn the values, behaviour and lifestyles required for a sustainable future and positive societal transformation.

\footnotetext{
${ }^{2}$ See the "Bonn declaration on university-enterprise cooperation in the context of lifelong learning", LLL, see above the ANNEXE I.

3 See the First European University-Business Forum Took Place in February 2008 and Universities and Businesses Meet at European Forum To Discuss Cooperation, Brussels, 5-6 February 2009.

${ }^{4}$ See Http://Ec.Europa.Eu, About the European Qualifications Framework (EQF) European Institutions in 2008, the EQF Is Being Put in Practice across Europe
} 


\author{
Alessandro Figus \\ Beyond Bologna: The Sustainable University Enterprises Partnership
}

Even though several projects aim at the university management reform, pedagogical components are also addressed: i.e., practice-based curriculum; the balance of theoretical knowledge with market realities and professional skills; the practice of communication and teamwork needed for industry success. This will result in improvement of the capacity of HEIs to adapt to changing needs; switch to student-centred learning, regarding pedagogy, curriculum, quality assurance, funding, and infrastructure; better return on investment in $R \& D$; the realisation of cost savings in training. Finally, we remark that in Europe, there are about 300 to 400 Regional Labour Market Observatories that generate data periodically to ensure transparency in the regional labour markets. In addition to information about branches, employees and unemployment; data on key industries and future qualifications are also taken into account. Regional Labour Market Observatories often work very isolated from each other (Mathejczyk and Schmid 2007; Larsen et. al., 2008). Thus, resources cannot be shared and it is not possible to find synergies through jointly developing concepts and implementation.

Furthermore, differences in data concepts and structures between observatories and regions show up, creating more difficulties in trans-regional comparisons. Instead of this, the conceptual idea is also to promote the partnership between the University and the Labour Market, because of the set of indicators which can be applied in youth monitoring. Youth monitoring is now important in many European regions and will be vital in Eastern Europe. As it shows, the European experience, the creation of Employability Monitoring Centres, Start-up Centres can be a guide for the students both during the first impact with University World and during the first impact with the Work world. The Centres that we are willing to create in Eastern Europe and especially in Moldova have particular relevance after the financial crisis as youth unemployment has increased significantly and employment for young people (students today, workers tomorrow) has become a difficult issue.

In order to provide a high-quality involvement of stakeholder, it is better to include in the partnership the ministry of education, the ministry of economy, the representative enterprise from the Eastern Europe in the work market. To assure a university - enterprise really cooperation the stakeholders will have an important voice in formulating the mission and strategy. The involvement of the representatives from those identified creating the target groups is described in the above activities (USAID, ANNEX II).

\title{
3. CONCLUSIONS
}

Today the labour market is a very central element in Higher Education policies. Partnership of Higher Education and Industry, thus, became strategic labour market. Most government policies are starting from the simple idea on how to assure that the system as a whole delivers the kind of graduates that are needed in modern knowledge intensive European societies.

In fact, demand for high-level skills is expected to grow meaning that a larger proportion of the working age population should have a higher level of qualification. The economic and cultural growth and the ability of renewal are the fundamental objectives of every EU countries, and these objectives should also strived in developing and in-transition countries of Europe. A significant contribution to the attainment of such objective can be brought by a suitable higher education quality that aims for the development of creativity and individual initiative, as well as the acquisition of competencies that improve the professional qualification of the teaching staff. Quality assurance and accreditation have increasingly become structural instruments to support the ties between higher education and the labour market. In conclusion, there should be more active policies in EU. There should be the workforce development strategy to encourage cooperative programmes between HE institutions and industry, and to develop mechanisms to support co-funding with employers and learners, to support initiatives by HE institutions to enhance the employability of students, to develop brokerage models, to develop regulatory frameworks and arrangements for HE to engage with enterprises. 


\author{
Alessandro Figus \\ Beyond Bologna: The Sustainable University Enterprises Partnership
}

\title{
REFERENCES
}

- Armenia, "Strategic Planning in Higher Education: Modern Experience and Perspectives", Tempus project "Environment Driven Strategic Planning at SEUA" (Tempus-Tacis JEP 250582004).

- Aylett, R., Gregory, K. (Eds), Evaluating Teacher Quality in Higher Education, London, Falmer, 1996.

- Bonn declaration on university-enterprise cooperation in the context of lifelong learning", 2006.

- Bruijn, Theo and Vicki Norberg-Bohm. "Introduction: Toward a New Paradigm for the Transition to a Sustainable Industrial Society?." Chap. 1 in Industrial Transformation: Environmental Policy Innovation in the United States and Europe. Cambridge, Mass.: The MIT Press, July 2005

- Chisinau (MD) EU Tempus Tacis Workshop, Standardele si calitatea in invatamintul continuu, Chisinau, Moldova, November 2007.

- Conference on Education Quality, World Bank for Reconstruction, Novosibirsk, Russian Federation, May 2003.

- Coordination of workshop"La metodologia della valutazione della qualità della formazione dei giovani in Europa. Giovani e mondo delle imprese in Europa tra est ed ovest", VII National Congress of Italian Society of Evaluation, Milano, march 2004.

- Cortese, A.D. "The Critical Role of Higher Education on Creating a Sustainable Future", Planning for Higher Education, 2003

- EU Tempus Meda Workshop, Training and the maritime work market : Mediterranean perspectives, Alexandria Egypt, November 2006.

- Figus A., Higher Education Quality and the world of work, in TOM 3, World Bank Quality Conference in Novosibirsk (RF), NSTU, Novosibirsk, 2003.

- Figus A., La metodologia della valutazione della qualità della formazione dei giovani in Europa. Giovani e mondo delle imprese in Europa tra est ed ovest, paper presented in the workshop by the Italian Society of Evaluation (AIV) "La rete e I'arcipelago: viaggio tra le pratiche della valutazione italiana", published on the website : http://www.valutazioneitaliana.it/iniziative.php, 2004.

- Figus A., Quality between higher education and the world market, in Standardele si calitatea in invatamintul continuu, IIC Moldova ISBN 9975-70-542-1, Chişinău, 2005, pp.53-61.

- High quality involvement of stakeholder by USAID ( see on the web site: http://www.equip123.net/), see ANNEXE II.

- International Conference «Italia-Russia nelle Regione di Kuban», Krasnodar, Kuban State University, July 2004.

- International Conference of Russian Economists, Soci (Russian Federation), February 2006.

- International Conference of Russian Economists, Soci (Russian Federation), 7st February 2004.

- Larsen, C., Mathejczyk, W., Kipper, J., Schmid, A.: Target Group Monitoring in European Regions. Empirical Findings and Conceptual Approaches, Rainer Hampp Verlag, Munich, 2008.

- Larsen, C., Mathejczyk, W., Schmid, A., Monitoring of Regional Labour Markets in European States. Concepts, Experiences, and Perspectives, Rainer Hampp Verlag, Munich, 2007.

- Leclercq, D., Pour une pédagogie universitaire de qualité, Sprimont, Mardaga, 1998. Moon, B. (edited by), Judging Standards and Effectiveness in Education, London, Hodder, 1999. Rapporto finale sulle attività di valutazione Campus, Roma, Conferenza dei Rettori delle Università italiane, 2000-2008.

- Mathejczyk, W., Schmid, A., Monitoring of Regional Labour Markets in European States. Concepts, Experiences, and Perspectives

- Rainer Hampp Verlag, Munich and Larsen, Target Group Monitoring in European Regions. Empirical Findings and Conceptual Approaches, 2008

- Sims, S.J., Sims, R.R. (Eds.), Total Quality Management in higher education: Is it working? Why or why not?, Westport Connecticut: Praeger Publishers, 1995.

- Tempus Tacis International Conference on «the Quality of Higher Education», Chişinău, April 2005; 


\section{Alessandro Figus}

Beyond Bologna: The Sustainable University Enterprises Partnership

- Van Weenen H. , Towards a vision of a sustainable university, International Journal of Sustainability in Higher Education, Vol. 1, Amsterdam, 2000.

- van Weenen H., Towards a vision of a sustainable university, International Journal of Sustainability in Higher Education, Vol. 1, Amsterdam, 2000.

- Zabriskie N.B. and Alan B.H. Developing Strategic Thinking in Senior Management. Long Range Planning Volume 24, Issue 6. 1991, CrossRef 